\title{
Opponent left-handedness does not affect fight outcomes for Ultimate Fighting Championship hall of famers
}

\section{Thomas V. Pollet* and Bart R. Riegman}

Department of Social and Organizational Psychology, VU University Amsterdam, Amsterdam, Netherlands

*Correspondence: t.v.pollet@vu.nl

\section{Edited by:}

Andrew C. Gallup, SUNY College at Oneonta, USA

Reviewed by:

Omar Tonsi Eldakar, Nova Southeastern University, USA

Keywords: handedness, fighting hypothesis, laterality, mixed martial arts, combat sports

\section{A commentary on}

Born to win? Testing the fighting hypothesis in realistic fights: left-handedness in the Ultimate Fighting Championship by Pollet, T. V., Stulp, G., and Groothuis, T. G. G. (2013). Anim. Behav. 86, 839-843. doi: 10.1016/j.anbehav.2013.07.026

This paper is a commentary on Pollet et al. (2013), where both the incidence of left-handedness and its effect on outcomes were analyzed. One of the drawbacks is that these analyses were largely cross-sectional with only a small number of fights for any given fighter. Here, we explore the effects of left-handedness on fight outcomes in a small sample of elite UFC fighters with multiple fights from the same fighter.

All UFC fights by the current 10 UFC hall of fame fighters were coded by the second author B.R. (with assistance of Thomas V. Pollet) from a variety of online sources (www.ufc.com; www.sherdog.com; www.mmajunkie.com; www.wikipedia. com) $(N=182$ fights $)$. The UFC hall of fame list consists of the most successful UFC fighters of all time and currently one non-fighter (UFC, 2014). For each fight we coded the outcome and handedness of the hall of famer and his opponent, if available. There were nine right-handed hall of famers and one left-hander (Royce Gracie). As there is only one left-hander we excluded his fights. Our analyses also exclude duplicate fights (i.e., hall of famers fighting one another). Central to our analyses is that we examine the effects of right-handers fighting left-handers, this is why we also exclude fights by Mark
Coleman, who in our dataset, as a righthander only fought right-handers. This leaves 75 fights with complete data on both fighters' handedness for analysis. The most straightforward test is a simple $\chi^{2}$ test for the $2 \times 2$ table. However, such a test does not take into account the nested structure of the data (i.e., fights belonging to the same hall of famer). Therefore, we also ran a Cochran-Mantel-Haenszel test (Agresti, 2002) and a Generalized Linear Mixed Model with binomial link (GLMM; McCulloch, 2006; Verbeke and Molenberghs, 2009), using the lme4 procedure in R 3.0.1 ( $\mathrm{R}$ Development Core Team, 2008; Bates et al., 2012). If we find some indication for a fixed effect of opponent handedness in a GLMM, after accounting for the nested structure of the data (random intercept), then this suggests that the opponent's handedness significantly influences the outcome. We also test a model whereby we model a random intercept for the opponent, In order to account for multiple appearances of an opponent, as well as a random intercept for the hall of famer (see Hox, 2010). The lme 4 package does not allow fitting quasibinomial models, we therefore also tested a GZLM with quasibinomial link, as over/underdispersion could affect the result from the GLMM. Given that our sample is (very) small we report one-tailed tests in favor of the hypothesis that left-handedness has an effect.

Hall of famers were not significantly less likely to win from left-handers (Figure 1; $\chi^{2}$ test $=0.17$; Monte Carlo bootstrapped one-tailed $p$-value based on 10,000 samples $=0.39$ ). The CochranMantel-Haenszel test also does not support the conclusion that handedness affects outcomes in our sample $(\mathrm{CMH}$ test, one-tailed $p=0.44$; estimate of common odds ratio $=0.813 ; 95 \% \mathrm{CI}$ (odds ratio) $=<00.01$ to 2.188 ). In the GLMM, with a random intercept for hall of famer, we found no evidence for a handedness effect $(B=-0.214( \pm 0.520)$; $Z=-0.412$, one-tailed $\quad p=0.34$ ). Accounting, for multiple appearances of the opponent or analyzing the data via a GZLM with quasi-binomial link does not alter this conclusion (respectively: $B=-0.454( \pm 0.628) ; Z=-0.723$, onetailed $p=0.235 ; \quad B=-0.214( \pm 0.527)$; $t=-0.407$, one-tailed $p=0.342$ ).

Our analyses further support the conclusion that currently there is little evidence for an advantage of left-handers in mixed martial arts (MMA) based on wins. Across all tests there is litthe suggestion that Hall of Famers were more inclined to lose from left-handers. A much larger sample by Baker and Schorer (2013) also found that, while left-handers are overrepresented in MMA, there is no relationship between handedness and fight outcomes. One of the drawbacks of the Baker and Schorer (2013) study, however, is that Simpson's Paradox (Simpson, 1951) could not be ruled out (see Kievit et al., 2013). The pattern between fighters could be markedly different than that within fighters. While the win ratios analyzed by Baker and Schorer (2013) could be similar between left-handed and right-handed fighters, it is possible that the pattern within fighters is markedly different. It should also be noted that some evidence from other combat sports suggests that handedness 


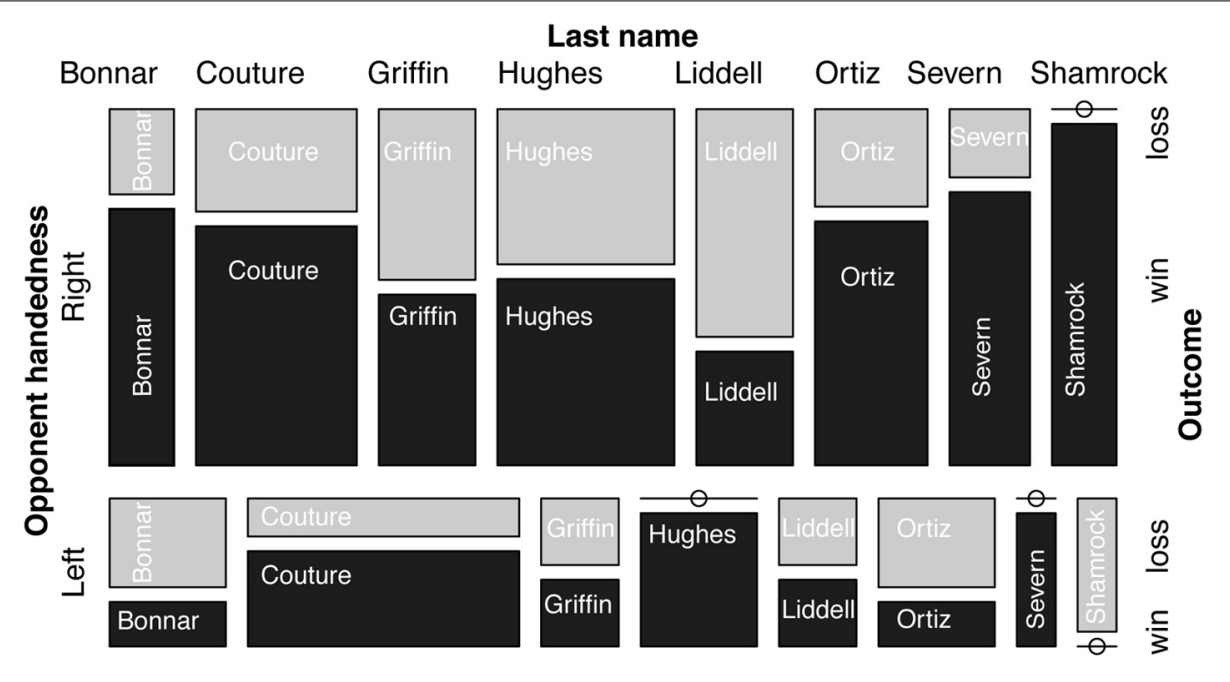

FIGURE 1 | A mosaic plot summarizing all the data (wins are in black, losses in gray; $\varnothing=$ no data available in that category) (Meyer et al., 2006, 2013; Hofmann, 2008; Wickham and Hofmann, 2011).

does affect outcomes (e.g., Wrestling: Ziyagil et al., 2010; Boxing: Gursoy, 2009), it is possible that MMA is substantially different from these other sports or that the conclusion for MMA is premature.

This small additional study has many limitations, including a very small sample size and its nature ("the elite"). Nonetheless, our study further corroborates that there is little indication for an effect of handedness on current outcomes in MMA, unlike what the "fighting hypothesis" (Raymond et al., 1996; Llaurens et al., 2009; Faurie et al., 2011; Faurie and Raymond, 2013; also see: Schaafsma et al., 2012; Groothuis et al., 2013) would lead us to suggest. However, the fighting hypothesis does not necessarily have to imply that left-handers have better outcomes currently in the MMA. While there is no measurable effect on current outcomes in MMA, left-handers were found to be overrepresented in three studies [Pollet et al., 2013: 20.4\% $(n=245)$; Baker and Schorer, 2013: 17.4\% $(n=1486)$; Dochtermann et al., in preparation: $17 \%(n=588)]$, as expected by the fighting hypothesis. This could imply that there is an equilibrium, whereby the benefit of lefthandedness has allowed an influx of lefthanders up until the point where the advantage has ceased. In order to establish whether this is plausible, further analyses are necessary (e.g., Dochtermann et al., in preparation), for example via longitudinal data on both amateurs and professionals. We therefore call for further research examining left-handedness in MMA to help understand why left-handers are overrepresented but, currently, not winning more fights. For now we conclude that, while left-handers are overrepresented in the UFC, and more broadly MMA, there is no substantial evidence that handedness reliably predicts fight outcomes.

\section{ACKNOWLEDGMENTS}

Thomas Pollet is supported by an NWO Veni grant (451.10.032). We thank Gert Stulp for helpful comments and thank Ned Dochtermann for sharing his working paper.

\section{REFERENCES}

Agresti, A. (2002). Categorical Data Analysis, 2nd Edn. New York, NY: John Wiley and Sons.

Baker, J., and Schorer, J. (2013). The southpaw advantage? Lateral preference in mixed martial arts. PLoS ONE 8:e79793. doi: 10.1371/journal.pone. 0079793

Bates, D., Maechler, M., and Bolker, B. (2012). Ime4: Linear Mixed-Effects Models Using S4 Classes. Available online at: http://lme4.r-forge.r-project.org/

Faurie, C., Llaurens, V., Alvergne, A., Goldberg, M., Zins, M., and Raymond, M. (2011). Lefthandedness and male-male competition: insights from fighting and hormonal data. Evol. Psychol. 9, 354-370.

Faurie, C., and Raymond, M. (2013). The fighting hypothesis as an evolutionary explanation for the handedness polymorphism in humans: where are we? Ann. N.Y. Acad. Sci. 1288, 110-113. doi: 10.1111/nyas. 12159

Groothuis, T. G. G., McManus, I. C., Schaafsma, S. M., and Geuze, R. H. (2013). Fighting the fighting hypothesis: how well does the fighting hypothesis explain the existence of lefthanded minorities in human populations? Ann. N.Y. Acad. Sci. 1288, 100-109. doi: 10.1111/nyas. 12164

Gursoy, R. (2009). Effects of left-or right-hand preference on the success of boxers in Turkey. Br. J. Sports Med. 43, 142-144. doi: 10.1136/bjsm.2007. 043547

Hofmann, H. (2008). "Mosaic Plots and their variants," in Handbook of Data Visualization Springer Handbooks Comp. Statistics, eds C. Chen, W. Härdle, and A. Unwin (Berlin, Heidelberg: Springer), 617-642.

Hox, J. J. (2010). Multilevel Analysis: Techniques and Applications. London: Taylor and Francis.

Kievit, R. A., Frankenhuis, W. E., Waldorp, L. J., and Borsboom, D. (2013). Simpson's paradox in psychological science: a practical guide. Front. Psychol. 4:513. doi: 10.3389 /fpsyg.2013.00513

Llaurens, V., Raymond, M., and Faurie, C. (2009). Why are some people left-handed? An evolutionary perspective. Philos. Trans. R. Soc. B Biol. Sci. 364, 881-894. doi: 10.1098/rstb.2008.0235

McCulloch, C. E. (2006). Generalized Linear Mixed Models. New York, NY: Wiley Online Library.

Meyer, D., Zeileis, A., and Hornik, K. (2006). The strucplot framework: visualizing multi-way contingency tables with vcd. J. Stat. Softw. 17, 1-48.

Meyer, D., Zeileis, A., Hornik, K., Meyer, M. D., and KernSmooth, S. (2013). The vcd Package. 3. Available online at: http://cran.r-project.org/web/ packages/vcd/vcd.pdf Accessed January 23, 2014].

Pollet, T. V., Stulp, G., and Groothuis, T. G. G. (2013). Born to win? Testing the fighting hypothesis in realistic fights: left-handedness in the Ultimate Fighting Championship. Anim. Behav. 86, 839-843. doi: 10.1016/j.anbehav.2013. 07.026 
Raymond, M., Pontier, D., Dufour, A. B., and Moller, A. P. (1996). Frequency-dependent maintenance of left handedness in humans. Proc. $R$. Soc. London B Biol. Sci. 263, 1627-1633. doi: 10.1098/rspb.1996.0238

R Development Core Team (2008). R: A Language and Environment for Statistical computing. Vienna: R Foundation for Statistical Computing.

Schaafsma, S. M., Geuze, R. H., Riedstra, B., Schiefenhövel, W., Bouma, A., and Groothuis, T. G. G. (2012). Handedness in a nonindustrial society challenges the fighting hypothesis as an evolutionary explanation for left-handedness. Evol. Hum. Behav. 33, 94-99. doi: 10.1016/j.evolhumbehav.2011. 06.001

Simpson, E. H. (1951). The interpretation of interaction in contingency tables. J. R. Stat. Soc. Ser. B 13, 238-241. doi: 10.1038/168063d0
UFC. (2014). UFC Hall of Fame. Available online at: http://www.ufc.com/fighter/hallOfFame [Accessed January 17, 2014].

Verbeke, G., and Molenberghs, G. (2009). Linear Mixed Models for Longitudinal Data. New York, NY: Springer.

Wickham, H., and Hofmann, H. (2011). Product plots. Vis. Comput. Graph. IEEE Trans. 17, 2223-2230. doi: 10.1109/TVCG. 2011.227

Ziyagil, M. A., Gursoy, R., Dane, Ş., and Yuksel, R. (2010). Left-handed wrestlers are more successful. Percept. Mot. Skills 111, 65-70. doi: 10.2466/04.05.19.25.PMS.111.4.65-70

Conflict of Interest Statement: The authors declare that the research was conducted in the absence of any commercial or financial relationships that could be construed as a potential conflict of interest.
Received: 03 March 2014; paper pending published: 21 March 2014; accepted: 08 April 2014; published online: 30 April 2014.

Citation: Pollet TV and Riegman BR (2014) Opponent left-handedness does not affect fight outcomes for Ultimate Fighting Championship hall of famers. Front. Psychol. 5:375. doi: 10.3389/fpsyg.2014.00375

This article was submitted to Evolutionary Psychology and Neuroscience, a section of the journal Frontiers in Psychology.

Copyright (c) 2014 Pollet and Riegman. This is an openaccess article distributed under the terms of the Creative Commons Attribution License (CC BY). The use, distribution or reproduction in other forums is permitted, provided the original author(s) or licensor are credited and that the original publication in this journal is cited, in accordance with accepted academic practice. No use, distribution or reproduction is permitted which does not comply with these terms. 